\title{
Valencias identitarias en Xoguetes pra un tempo prohibido, de Carlos Casares
}

\author{
Identitarian valences in Xoguetes pra un tempo prohibido, \\ by Carlos Casares
}

\author{
Mar FERNÁNDEZ VázQuez \\ Universidade de Santiago de Compostela \\ Centro Ramón Piñeiro para a Investigación en Humanidades \\ margramanet2004@yahoo.es
}

[Recibido, xuño 2010; aceptado, setembro 2010]

\section{RESUMO}

Este artigo repara nas valencias identitarias de Xoguetes pra un tempo prohibido e salienta as achegas de Casares á configuración do sistema literario galego.

PALABRAS CHAVE: Valencia identitaria, Carlos Casares, literatura institucionalizada, sistema literario galego, narrativa galega de posguerra, novela de formación.

FERNÁNDEZ VÁzqueZ, M., (2011): "Valencias identitarias en Xoguetes pra un tempo prohibido, de Carlos Casares". Madrygal (Madr.), 14: 71-79.

\section{RESUMEN}

Este artículo se detiene en las valencias identitarias de Xoguetes pra un tempo prohibido y destaca las aportaciones de Casares a la configuración del sistema literario gallego.

PALABRAS ClAVES: Valencia identitaria, Carlos Casares, literatura institucionalizada, sistema literario gallego, narrativa gallega de posguerra, novela de formación.

FERNÁNDEZ VÁzQuez, M., (2011): "Valencias identitarias en Xoguetes pra un tempo prohibido, de Carlos Casares". Madrygal (Madr.), 14: 71-79.

\section{ABSTRACT}

This paper examines the identity valences of Xoguetes pra un tempo prohibido, and it stands out Carlos Casares' contributions to the conformation of Galician literary system.

KEY WORDS: Identity valences, Carlos Casares, adults' literature, Galician literary system, postwar Galician narrative, bildungsroman.

FERNÁNDEZ VÁzQueZ, M., (2011): "Identitarian valences in Xoguetes pra un tempo prohibido, by Carlos Casares". Madrygal (Madr.), 14: 71-79.

SUMARIO: 1. Introdución. 2. A literatura galega institucionalizada e a produción de Carlos Casares. 3. Valencias identitarias de Xoguetes pra un tempo prohibido (1975). 4. Conclusións. 5. Referencias bibliográficas. 


\section{INTRODUCIÓN}

Carlos Casares Mouriño (Ourense, 1941-Vigo, 2002) redactou sempre en galego, tanto literatura para adultos como literatura infantil e xuvenil, ademais de ser tradutor literario de clásicos universais, ensaísta, editor crítico de biografías e colaborador xornalístico, entre outras actividades socio-político-culturais.

Este artigo céntrase na estratexia cultural que Casares empregou na súa produción para axudar a configurar o sistema literario galego, aspecto relacionado cos mecanismos empregados por el para se facer parte do campo literario (Bourdieu, 1991: 33-46) ou para conseguir que as súas obras se inclúan no "repertorio cultural" do que a literatura forma parte (Even-Zohar, 1979).

Asumido o concepto de ideoloxema ${ }^{1}$, repárase en Xoguetes pra un tempo prohibido (1975) porque Casares tematiza valencias identitarias cando ficcionaliza vivencias propias da ditadura e amosa distintas olladas dos grupos sociais da época, ao tempo que achega innovacións intertextuais e formais e variantes diatópicas ourensás.

\section{LITERATURA GALEGA INSTITUCIONALIZADA ${ }^{2}$ E PRODUCIÓN DE CASARES EN 1975}

Antes de entrar na análise, achegarase unha breve contextualización da novelística galega en 1975, e perfilarase a produción de Casares até ese ano.

Camiño Noia (2000: 93 ss.) apunta que entre os anos 1950-1970, grazas ao labor de "sete pequenas empresas editoriais" por tentar reconstruír a cultura galega, saíron do prelo algunhas narracións innovadoras. Sitúa a Casares na Nova Narrativa Galega (en adiante NNG) ${ }^{3}$ e afirma que o punto de partida desta corrente se sitúa na "crise das formas tradicionais da literatura", que deriva "do desenvolvemento da linguaxe cinematográfica", tendo como motor de arrinque a Europa cultural dos anos 50. Tamén X. Sucasas (1965) incluía na NNG os libros de Casares, entre outros escritores que tentaban plasmar na literatura galega as técnicas innovadoras de escritores europeos e americanos como Kafka, Sartre, Camus, Faulkner ou Robbe-Grillet (Tarrío Varela, 1994, pp. 367-368; idem, 2003).

Como non se pode afirmar con rotundidade que a NNG constitúa unha "escola" ou un "grupo", observaranse os seus integrantes como unha Generationenseinheit (Karl Mannheim, 1928) ou "unidade de xeración", entendida como "cada uno de los grupos concretos que, dentro de una cierta conexión generacional y desde una afinidad compartida y compacta, manifiesta reacciones unitarias ante los acontecimientos históricos, sociales, culturales..." (Casas: 1997, 37-38).

Noia (2000) conclúe que algúns textos de Suárez-Llanos ou Casares, "os menos vangardistas dos novos narradores galegos", comparten a localización das súas historias en espazos recoñecíbeis na España da posguerra, e que empregan o monólogo interior (tamén Tarrío Varela, 1994, p. 368) á hora de narrar con obxectividade cinematográfica. Como xa o fixeran outros estudiosos anteriormente (p. ex., Tarrío Varela, 1994, p. 206; Vilavedra, 1999), López Sández (2006: 57) lembra que Carré Alvarellos (1926) "manifestouse sobre a necesidade de incorporar a cidade á novela galega e, con ela, as clases medias e a burguesía", e afirma que Casares "acolle na súa produción a realidade urbana e suburbial" (p. 58).

Pese á súa escasa recepción literaria (agás Vento ferido e Lonxe de nós e dentro, de Suárez-Llanos) a NNG contribuíu á configuración do sistema literario galego.

Noia (2000) considera que non se pode estabelecer unha clara distinción na produción novelística de Casares, se non se presta atención aos recursos estruturais dos que se serve. Encadra Xoguetes... no segundo período, xunto a $O s$ escuros soños de Clío e Ilustrísima, caracterizado pola linealidade narrativa nun esquema máis tradicional e deixando un pouco de lado a experimentación técnica.

\footnotetext{
1 "Partindo do uso que deste termo fan Bakhtín e o seu círculo, Julia Kristeva (1969) considera o texto un ideoloxema, o que implica que só pode ser comprendido dende a súa inserción intertextual na totalidade sociohistórica. Así, na novela dáse unha intersección entre o conxunto extra-novelesco e o novelesco: esta relación de intertextualidade constitúe o ideoloxema da novela." (Equipo Glifo, 2006, "ideoloxema". Última consulta: 14-II-2010).

${ }^{2}$ Como a adxetivou en varios traballos Roig (2008), por citar un dos últimos traballos que fala da educación literaria e historias literarias onde reflexiona sobre a tardía aparición das historias literarias na LIX.

3 Termo cuñado por Sucasas (1965). Véxase ademais a opinión discordante de Casares (Álvarez Pousa, 1969), aínda que anos máis tarde recoñeceuse dentro dela (Tarrío Varela, 2003).
} 
Queda para a reflexión unha idea apuntada por Ma Xosé Queizán (1979): “Galicia está presente no desequilibrio, na inseguridade, na alienación dos simbólicos seres torturados e perdidos nas narracións", e unhas palabras de Rodríguez Mourullo nunha entrevista de 1982: "Era un pouco o afrontar dende o plano narrativo problemas universales pero vistos desde a idiosincrasia do home galego".

A seguir, perfílanse algúns datos biográficos e literarios que teñen un claro reflexo e ficcionalización nesta novela. Aínda que Casares naceu en Ourense no ano 1941, pasou a súa infancia e adolescencia na localidade ourensá de Xinzo de Limia. Ingresou no Seminario conciliar de Ourense en 1952 e durante eses anos de estudo na cidade das Burgas coñeceu a Vicente Risco, que influíu na súa vocación de escritor e na súa achega ao galeguismo ${ }^{4}$.

Durante a súa estadía en Madrid para comezar a carreira de Filosofía e Letras, foi un habitual do café Gijón onde se relacionaba coa intelectualidade española da época. Cando volve a Galicia en 1965 para continuar Filoloxía Románica na universidade compostelana, traía xa un bo coñecemento da narrativa americana e europea do século $\mathrm{XX}$ e unha gran fascinación por José $\mathrm{M}^{\mathrm{a}}$ Valverde e por José Luis Aranguren, profesores universitarios que protagonizaran en 1964 un coñecido enfrontamento co réxime de Franco.

En Compostela estabeleceu unha fonda amizade con Ramón Piñeiro (ao que xa visitaba dende 1961), organizou actos culturais como membro da Asociación Democrática de Estudiantes Universitarios e comezou a publicar, primeiro, poemas, e despois relatos na revista Grial. Continuou a ler literatura contemporánea a través de traducións arxentinas e en 1967 publicou Vento ferido, baixo os presupostos narratolóxicos de Alain Robbe-Grillet, en Pour un nouveau roman (1963). En 1968 gañou o I Concurso Nacional de Contos Infantís d'O Facho con A galiña azul, en 1969 publicou a novela Cambio en tres, en 1972 comezou a súa faceta como tradutor con $O$ principiño, de Antoine de Saint-Exupéry, e en 1973 acadou un novo premio infantil d'O Facho, nesta ocasión na modalidade de teatro, con As laranxas máis laranxas de todas as laranxas.

\section{VALENCIAS IDENTITARIAS EN XOGUETES PRA UN TEMPO PROHIBIDO (1975)}

Xoguetes pra un tempo prohibido (1975) supúxolle o Premio de Narrativa "Galaxia, 25 anos" e, un ano despois, o Premio da Crítica Galega. Cando Casares publicou esta novela xa era considerado un escritor de "primeira liña da narrativa galega do momento" (Platas Tasende: 1998, 15).

Sen articulación en capítulos, a novela narra a vida de Elías Paz, un rapaz de pobo, introvertido e perdido polo influxo do ambiente familiar e social. Para Silvia Gaspar (2000: 155) inaugura a denominada "novela da época posfranquista" (que sitúa entre 1975 e 1979), xa que conviven criterios socioliterarios sen que exista un corpus narrativo cun único perfil literario.

Este artigo repara nas seguintes valencias identitarias: a xeografía (pobo/vila vs cidade), os personaxes, a tipoloxía da novela, a temática, a intertextualidade, a linguaxe e as innovacións narrativas, que serán tratadas independentemente, aínda que determinados momentos da novela tematizan varias valencias a un tempo.

Antes de entrar na análise do texto, repárase na relevancia e significación dos peritextos do libro. O título simboliza a perda da infancia do protagonista, quen carece de xoguetes, tendo só como lecer a crítica opresora dalgúns elementos relixiosos que padece a diario (xogar ao escondite na igrexa tras un altar, remedar ao cura confesando, burlarse das arengas do cura, etc.) e ademais é expulsado do Paraíso, a causa dunha sociedade do pasado, condicionada por unha relixión represora que vía maldade en cousas inocuas (falar de fútbol, aínda que se xogase no seminario) e que estaba marcada pola idea do "pecado". Na análise semántica do título, Xavier Carro (2009: 73-75) alude á intertextualidade coas lecturas e filmes dos que gustaba Casares e apunta que este opta por semas de connotacións negativas para conciliar a "ética e estética" do seu compromiso social.

Nun peritexto epigráfico de Jean Paul Sartre, determina o final da historia, marca a importancia da relixión e explica que Casares escollese como protagonista un rapaz que se vai vendo medrar ao longo da novela.

\footnotetext{
4 Casares (1981) coñecera a Vicente Risco, que xa fora profesor do seu pai, ao gañar un certame literario no que o autor de $O$ porco de pé formaba parte do xurado. Desde ese momento, comezou a asistir ás súas tertulias no café Parque.
} 
En conxunto, os peritextos son obra dun narrador omnisciente que tenta captar o lectorado e que confía nos seus coñecementos culturais para desvelar as constantes intertextualidades da novela ${ }^{5}$.

\section{A XEOGRAFÍA}

A novela presenta tres etapas na vida de Elías (como neno na vila, como mozo no seminario ourensán e como adulto na universidade compostelá), que, á súa vez, conforman unha microestrutura, ao xeito da estrutura clásica de "presentación, nudo e desenlace", onde o protagonista debe cada vez comezar de novo: "En adiante terás que aprender todo de novo, ter conta de non esquecer canto viviras pra poder seguir adiante. Era o importante saber que máis alá do muro permanecía todo igual" (p. 30). Terá que se enfrontar a mundos, situacións e personaxes descoñecidos, feito que contribúe a marcar o deambular sen rumbo fixo, errático e perdido de Elías a nivel persoal e intelectual, nunha clara intertextualidade con L'étranger (1942), de Albert Camus ou con Ulysses (1922), de James Joyce, autores dos que gustaba Casares.

Estabelécese un primeiro paralelismo entre o personaxe de Elías e Casares cando o narrador en segunda persoa adianta que Elías vai marchar para o seminario, que supón na narración o cambio xeográfico de vila á cidade ("ti, o nacido nunha pequena vila ourensá hai catorce anos", p. 20), xa que Casares tamén estivo no seminario de Ourense dende os once.

Iso ocorre na segunda parte da novela. Se ben da cidade onde se localiza o seminario non dá o autor datos nidios para ubicala con total seguranza, polo tempo que tarda a nai en chegar dende pobo e xa que afirma que Elías nacera "nunha vila ourensana", debe tratarse de Ourense, estabelecéndose así unha nova nota autobiográfica. A transición que supón a adolescencia no seminario como interno significa unha etapa a medio camiño entre a vila da primeira etapa da infancia (á que volve nunha analepse que ten como nexo de unión a Loló) e a madureza coma estudante universitario en Compostela.

A terceira etapa comeza cando marcha no tren a Compostela para cursar unha carreira universitaria (nova coincidencia con Casares), cidade claramente identificábel por se nomear rúas e lugares facilmente recoñecíbeis como a rúa do Vilar, a rúa Nova, co Teatro Principal, a Ferradura, a rúa Doutor Teixeiro ou a praza do Toural.

\subsection{OS PERSONAXES}

Casares creaba personaxes-arquetipo que tiñan un maior ou menor grao de desenvolvemento segundo as necesidades argumentais, temáticas ou estilísticas de cada obra, e por medio deles amosaba as súas críticas contra a sociedade e transmitía valores. Como apunta Roig (2004: 91) ao analizar "A galiña azul", este conto constitúe "un alegato contra a uniformidade e unha defensa da diferencia e da liberdade, dereitos polos que o autor loitou en vida dende diferentes ámbitos". Palabras semellantes emprega Xavier Carro (2009: 72) cando apunta que en Xoguetes para un tempo prohibido "atopamos moitos temas e motivos que logo serán recorrentes no seu universo novelesco como son a inocencia, a infancia, o autoritarismo, a delación, a intolerancia, a violencia e a amarga realidade dunha sociedade vixiada e reprimida polo franquismo". Así Don Walter é un exemplo de figura opresora, igual que o profesor Smith na serie protagonizada polo neno inventor Toribio ou que Manolito Listón n'A galiña azul, fronte a personaxes solidarios e tenros, como son os veciños que apoian a galiña azul ou o peixe da fonte do xardín do citado volume de contos infantís.

A falta de consideración co idioma galego é un dos variados temas que a voz do narrador omnisciente critica dun xeito fluído nas páxinas 116-120:

que o galego é idioma e non dialecto; de que o galego sirve prá poesía pero non pró ensaio; de que o galego sirve para todo como calquera outra lingua; de que se lle debía ensinar ós nenos na escola; de que eso é un disparate; de que non é tal disparate; de que no tempo do universalismo non imos andar con localismos;

Esta invocación e eses desexos de prosperidade, en ton de arenga patriótica, lembran a necesidade que sentiron Casares e outros escritores galegos ao tentar romper coa imposición de Castela na

\footnotetext{
${ }^{5} \mathrm{Na}$ nota final da novela lemos: “[...] inclúense dous textos [...] que o lector identificará con facilidade, como ocurrirá con algúns versos ou frases [...]" (p. [153]).
} 
loita por fundar a "comunidade imaxinaria" (Anderson, 1993: pp. 17-25, 68-76 e 228-258) que soñaban con anhelo para Galicia, reivindicando o labor que estaban chamadas a desempeñar as elites intelectuais.

A consideración de que en Lita se unen o amor e o compromiso político e social na clandestinidade para lograr un futuro esperanzador ("Días e noites de incansable traballo a favor da humanidade, peligrosas visitas a non menos peligrosos pisos, encontros sixilosos con apóstolos inter pares, atentas escoitas a sospeitosos pasos", p. 100) lembra as accións emprendidas por Casares contra o SEU ou as mobilizacións nas revoltas universitarias do ano 1968.

Da serie de persoeiros nomeados nas páxinas 106-107 cómpre reparar en cómo se percibían persoas situadas ideoloxicamente á outra banda: o filósofo Aranguren ("o filósofo inxustamente acusado de amargado"), Sartre ("extrábico-diverxente") e Castelao ("irmán Daniel na praia de Rianxo"), entre outras.

Casares chega a dar conta da visión que teñen de España fóra, cando introduce ao amigo holandés de Mara que vén a estudar a España "a ver fascistas" (p. 144).

Mesmo existen fragmentos que constitúen unha ficcionalización de elementos reais da vida de Casares; así a disputa na novela entre don Nemesio e o Parranda que reflicte o que lle ocorrera a Benigno, un compañeiro do avó paterno de Casares (Calvo: 2003: 24).

\subsection{A TIPOLOXÍA NARRATIVA}

Esta novela respecta maioritariamente a linealidade da historia narrada (aínda que existen saltos temporais e pequenos flashes sen unha localización cronolóxica concreta) e esta orde, ademais de marcar a estrutura, reflicte que se trata dunha novela de formación e introspección do personaxe de Elías Paz.

Cando Elías ingresa no ambiente universitario, actúa como un espectador -como se estivese nunha sala de cine- que se dedica a contemplar a nova realidade santiaguesa, mais sente que non conta con tempo de abondo para lles atopar nome ás cousas, por iso está confuso: "E ti eras unha morea de palabras mortas, de tempo ancorado na memoria, de respostas inútiles, de medo...", p. 85.

Casares recorre constantemente ao emprego do fluír da conciencia, por exemplo cando exhorta ao protagonista a mudar o seu pensar e sentir, ao cumprir a maioría de idade: mándaselle esquecer a Rudyard Kipling -referente infantil- e ser un home -ler Ortega y Gasset-: "rompas amarras e te vaias mar adentro a gozar de tempestades hastra agora tan inxustamente apostrofadas.", p. 88.

Por estas e outras situacións semellantes, conclúese, en sintonía con Carro (2009: 73-75) que se trata dunha "historia de aprendizaxe", unha "novela experimental", "testemuñal", "de desengano", que reflicte a "crise existencial" e a "continua perda" que experimenta Elías.

\subsection{A TEMÁTICA}

A relixión é un tema constante na produción de Casares e está presente tanto en obras para os máis novos, como O can Rin e o lobo Crispin (1983), coma nas da literatura institucionalizada $\mathrm{Os} \mathrm{escu-}$ ros soños de Clío (1979) ou Ilustrísima (1980).

O momento en que Elías volve a casa porque non atura a presión e o ambiente de represión e prohibición que derivan en castigos se non se cumpre o regramento estabelecido, preséntase como unha volta á "terra prometida", e o seu sufrimento compárase co do pobo de Israel baixo a tiranía exipcia, que mesmo chega a mover á compaixón a Iaveh.

Neste retorno de Elías á vila estabelécese un contraste entre a santidade de Loló e a alma pecadora de Elías, reflectido en dous momentos clave: o desgusto experimentado pola súa familia -novas reconvencións bíblicas do cura-, e a "piedade edificante" de Loló despois de que o Pavesa lle baleirase o ollo dereito.

A relixión opresora está sempre presente nas vidas dos personaxes, como se observa nos insultos que lle dirixe don Telesforo no sermón da misa a Paco Churri "sin mentalo" (p. 59), chamándolle "alma negra" -en referencia ao episodio con don Walter da primeira parte da novela-. É tal o influxo opresor da relixión que mesmo a avoa Enriqueta se vai entrevistar co Gobernador Civil para que desterren a Paco Churri, e despois don Telesforo felicita ás "damas virtuosas e cristianas" (p. 61).

Esta presenza case omnipresente de Deus e da relixión reaparece na crise que experimenta Elías $\mathrm{Paz}$, que ten unha correspondencia clara coa que sufriu o propio Carlos Casares ao rematar a carreira e ter que enfrontarse á vida adulta (Calvo: 2003, 125) e que coincidía tamén cun momento no que saía cunha rapaza -como Elías con Chedes, e vén- 
dose ás agachadas con Chicha-: "Podías chorar toda a noite no teu cuarto, podías preguntarlle a Deus por qué tiñan que ser tan acedas as derrotas, [...] Pero Deus non respondía.”, pp. 79-80. O deambular errático e perdido de Elías Paz explica o agónico, sepulcral e solitario final de Xoguetes pra un tempo prohibido:

acordándote da Virxen porque vas morrer estúpidamente didiante dun espello nesta habitación empapelada de flores malvas onde mañá dirán que te atoparon cunha mueca de risa na curva superior da boca e cunha pucharquiña de auga debaixo do ollo dereito sobre a sábana. (p. 151)

Cando narra a lectura na pensión de libros prohibidos, xorde, unha vez máis, un narrador omnisciente como se fose a voz da conciencia de Elías: "expulsado unha vez máis do paraíso, sinalada con cruz polo anxo a túa porta, poderías dedicarte ó vicio secreto e perverso polo xuzgador condenado", p. 117.

E amósase a rebeldía de Elías co seu eu, nun especie de desdobramento do ying e o yang, o ben e o mal, que configuran a súa personalidade confusa e perdida que vaga sen un rumbo fixo nas seguintes liñas: "Es cómico, es estúpido e nunca me engañaches. Dille, anda, dille ós teus dilixentes maestros que multipliquen os castigos. Fíxate cómo os adxectivos cambio. Mira como mal traduzo os ben compostos versos." (p. 91). Ese fragmento supón un mofa grotesca, surrealista e absurda da realidade que imperaba até aquel momento. E así mesmo enlaza co humor e a ironía tan característicos da literatura infantil de Casares (como A galiña azul ou As laranxas máis laranxas de todas as laranxas), os xogos sinestésicos e lingüísticos do final do relato "Monólogo", de Vento ferido (Casares, 1967 [1985]: 38) e lembra as borracheiras filosóficas de Max Estrella acompañado de don Latino de Hispalis en Luces de bohemia (1920).

Tamén se relata de xeito detallado o aborto de Mara, tras ser violada por Pepe Bobillo, polo cal o P. Esteban a condena pese ás causas que esta alega:

Cando despertóu nunha sala blanca, o mundo recomenzaba, e no principio era o pranto da súa nai condenada en vida por autorizar o crimen, $[. .$.$] nin$ sequera pola chamada indicación ética sería lícito facelo, nin sequera en casos rodeados das agravantes circunstancias que Mara asegura se deron nela. (pp. 136-137)

\subsection{A INTERTEXTUALIDADE}

$\mathrm{Na}$ etapa de madureza persoal e intelectual concéntrase a maior parte das alusións intertextuais ao cinema, á música, á literatura e filosofía estranxeiras, castelás e galegas. Alúdese ao filme No me digas adiós, baseado na novela Aimez-vous Brahams?, de Françoise Sagan. E soa a música de Duke Ellington, Coltrane, Joan Baez, Louis Amstrong, Frank Sinatra, Mina, a trompeta de Billy Parker e o blues de Muddy Waters.

A celebración do aniversario de Chedes serve para introducir a personaxes recoñecidos na sociedade do momento: así Pepito Almidonado compara a Chicha e Lola Flores e escóitanse discos de Pérez Prado. Ou cando Elías ten remordimentos e decide non ver películas da "rubia tola" - en referencia a Marilyn.

A visión cinematográfica que aparece en Cambio en tres tamén emerxe no xogo de planos de Xoguetes pra un tempo prohibido, o mesmo que ocorre coa polifonía de voces narrativas, que xa estaba presente dende Vento ferido, convivindo tamén coa ruptura temporal.

Cando aparece o personaxe de Andrés Mariño, dille a Elías se aínda non superou $L$ étranger, de Camus, obra que Elías tiña en tradución castelá nova coincidencia con Casares, que a lera en traducións arxentinas.

Estabelécese unha comparación intertextual co Ulises grego ao que lle asubiaban as sereas nas páxinas 88-89. E mesmo se apela a Elías como o escollido, un heroe, un profeta que faga camiñar ás novas xentes por unha senda nova, distinta á do pasado, como Karl Marx: “ $\mathrm{O}$ treverisián filósofo tan escandalosamente ignorado!” (pp. 89-90).

Estas referencias reflicten a personalidade de Casares: un home culto, aberto ao mundo que o rodeaba e a Europa, interesado por outras linguas e preocupado por coñecer outras manifestacións artísticas.

\subsection{A LINGUAXE}

O máis salientábel, neste sentido é que Casares decide elevar a categoría de lingua escrita a variedade dialectal da súa comarca, dándolle voz literaria ás persoas reais nas que se basean os personaxes da novela, considerando o galego un idioma con plenos dereitos, fronte quen o tildaban de dialecto (Xoguetes..., 118-120). É dicir, emprega a variedade dialectal do bloque central, da área lucu- 
auriense (Fernández Rei, 1990). Como constante do seu estilo, tamén aquí o léxico destaca pola sinxeleza.

\subsection{AS INNOVACIÓNS NARRATIVAS}

Un dos logros da novela é a presenza dun narrador en segunda persoa que se dirixe a un "ti" (identificábel co lectorado ou co protagonista) para lle avanzar datos futuros ou increpalo. Até a dramática escena final, o lectorado non descobre, con sorpresa, que o diálogo do narrador (ao que considerara omnisciente) durante toda a novela é en realidade un monólogo interior que o protagonista mantivo consigo mesmo nun desdobramento da súa persoa, como se se tratase dun ser bipolar ou dobre, ou como se relembrase e castigase a si mesmo mentalmente ou verbalizando as súas arengas.

Malia o texto axustarse maiormente a unha orde lineal, existen saltos no tempo, como un que sorprende o lectorado porque non vai precedido de ningunha pista previa, descoñécese canto tempo transcorreu dende o derradeiro fragmento narrado e non se descobre a finalidade do flash-forward.

Resta indicar que se observa unha caracterización simple dos personaxes. Limítase a bosquexalos, a dotalos dalgunha característica esencial que os defina (por exemplo, a ideoloxía no caso de Tino Román e de Andrés Mariño; unha virtude, en Loló; un defecto ou unha falta de virtude, en $\mathrm{O}$ Calamidá ou en Elías), algo habitual na súa escrita tanto para adultos coma para os máis novos, xa que Casares gustaba das pequenas miudezas descritivas e da xerarquización gradual e ordenada da historia.

\section{CONCLUSIÓNS}

Con Xoguetes pra un tempo prohibido Carlos Casares conseguiu fundar a "novela da súa unidade de xeración", é dicir, "pode considerarse unha novela autobiográfica dunha xeración enteira" (Calvo: 2003, p. 127), "a novela moderna dos universitarios do meu tempo" (Platas Tasende: 1998, 22). Conségueo grazas ao humor e á ironía, e a ser un gran narrador oral -como o seu avó paterno
Herminio-, xa que afirmaba "eu teño dende sempre unha visión puramente narrativa da vida" (Platas Tasende: 1998, 22).

$\mathrm{O}$ escritor ourensán presenta un informe bastante obxectivo da vida que lles tocou vivir aos do seu tempo: un Ruedo Ibérico de personaxes e circunstancias socio-político-culturais que son facilmente identificábeis con elementos da realidade que rodeaba os galegos entre os anos 60 e 70, de aí que a primeira localización da novela sexa unha vila $^{6}$ do interior de Galicia. Ao describir o acontecido durante aqueles anos, bota man tanto das súas lembranzas coma da xente que coñecía, para crear así unha "Historia" do que pasaba naqueles anos convulsos e represivos.

As innovacións, á parte da preocupación estilística do escritor, son un xeito de rachar as cadeas que tiveron sumida a Galicia durante a ditadura franquista, e de reivindicar a necesidade de camiñar en liberdade e de crear unha "comunidade imaxinada". Subxace o concepto de "nación" galega ${ }^{7}$, onde a lingua propia sexa un medio de comunicación e cultura, de aí que Casares opte por abrirse á Europa democrática para saltar as barreiras impostas a Galicia dentro do estado español.

Sen chegar á parodia da que fai gala o cineasta Federico Fellini en Amarcord (1973), ou ás deformacións grotescas no eido literario de Ramón María del Valle-Inclán, en Luces de bohemia (1920), de Vicente Risco en O porco de pé (1928) ou d'O espello do gato (2007), de Álvaro Lago (exemplos de obras con multiplicidade de personaxes e puntos de vista, ademais da crítica social, principalmente aos poderes xerarquizados), Casares sérvese da ironía e do monólogo interior para a súa crítica sen estendela aos personaxes que son vítimas dos acontecementos, sofren e tentan cambiar.

Elías é vítima da represión e prohibición que propugna a Igrexa católica. A súa actitude é a esperábel nel: é violento e traidor porque é o que lle tocou vivir. Sofre unha contradición interna entre o ben e o mal, de aí que vaia pola vida sen rumbo fixo, e remate sen ningunha esperanza posíbel -visión algo determinista do personaxe.

En conxunto pódese apuntar que as valencias identitarias galegas de Xoguetes pra un tempo

\footnotetext{
6 V. o poboamento en vilas e comarcas que destaca o xeógrafo Precedo Ledo (Murado, 2008: 20-21).

7 Véxase unha explicación práctica en Fernández Pérez-Sanjulián, Carme (2003), A construción nacional no discurso literario de Ramón Otero Pedrayo. Vigo: A Nosa Terra.
} 
prohibido constitúen pequenas pinceladas estilísticas, léxicas e temáticas que permiten falar dunha serie de ideoloxemas na produción de Casares, os cales aparecerían, nun segundo ou primeiro plano, segundo o sentido último de cada creación narrati$\mathrm{va}^{8}$, opinión que tamén recolle Sánchez Ferraces (2007: 86-95) ao analizar os "catro signos ideolóxicos" d'Os mortos daquel verán.

\section{REFERENCIAS BIBLIOGRÁFICAS}

\section{TEORÍA LITERARIA}

ANDERSON, Benedict (1993): Comunidades imaginarias: Reflexiones sobre el origen y la difusión del nacionalismo. México: Fondo de Cultura Económica.

Bourdieu, Pierre (1991): "Le champ littéraire", in Actes de la Recherche en Sciences Sociales. Volume 89, Num. 1.

CASAS, Arturo (1997): La teoría estética, teatral y literaria de Rafael Dieste. Santiago de Compostela: Universidade de Santiago de Compostela. Servizo de Publicacións e Intercambio Científico. Col. Lalia. Serie Maior 8.

EQuipo Glifo (1998, 2003): Dicionario de termos literarios, vol. I(A-D), vol. II (E-H), Santiago de Compostela: Centro Ramón Piñeiro para a Investigación en Humanidades. Xunta de Galicia.

- (2006, cont. de Equipo Glifo 1998, 2003): Dicionario de termos literarios. http://www.cirp.es/pls/ bdo2/f?p=DITERLI,

Even-ZohaR, Itamar (1979): "Polysystem Theory", in Poetics Today. I, 1-2, 287-310. Versión modificada, primavera 1990, in Poetics Today. 11, 1, 9-26. "Teoría de los polisistemas", trad. de Ricardo Bermúdez Otero, 1990.

KRISTEVA, Julia (1969): Semeiotiké. Recherches pour une sémanalyse. París: Seuil.

_ (1976): Le Texte du roman, approche sémiologique d'une structure discursive transformationnelle. París: Mouton.

Mannheim, Karl (1928): "Das Problem der Generationen”, en Kölner Vierteljahrshefte für Soziologie, vol. 7, 2-3. Incorporado a Wissenssoziologie: Auswahl aus dem Werk, ed. de K.H. Wolff, Berlín-Neuwied, Luchterthand, 1964. Trad. ao francés Le problème des générations, 1990, introdución e epílogo de Gérard Mauger. París: Nathan.

Roig Rechou, Blanca-Ana (2008): "Educación literaria e historias literarias", en A mi dizen quantos amigos ey. Homenaxe ao profesor Xosé Luís Couceiro, Santiago de Compostela: Servizo de Publicacións da Universidade de Santiago, pp. 333-342.

\section{BIBLIOGRAFÍA PRIMARIA}

CASARES [Mouriño], Carlos (1967): Vento ferido. Consulto $5^{\mathrm{a}}$ ed. 1985. Vigo: Galaxia.

(1975): Xoguetes para un tempo prohibido, portada de Luis Mariño, fot. portada Roberto Quintero, $2^{\mathrm{a}}$ ed. Vigo: Editorial Galaxia.

(1981): Vicente Risco. Vigo: Galaxia. Col. Conciencia de Galicia.

\section{BIBLIOGRAFÍA SECUNDARIA}

Álvarez Pousa, Luís (1969): “Carlos Casares o la metamorfosis gallega”, entrevista con Carlos Casares. La Voz de Galicia, 13 de xuño.

\footnotetext{
${ }^{8}$ Podería relacionarse coas palabras de Camiño Noia (2000) de que a finalidade de Casares sería "contar historias utilizando elementos da contorna" e enumera seis deles.
} 
CAlvo, Tucho (2003): Carlos Casares. O conto da vida. A Coruña: La Voz de Galicia. Col. Biblioteca Gallega.

CARRO, Xavier (2009): “Xoguetes para un tempo prohibido, unha novela clave da narrativa casariana", in Noia, Camiño, Olivia Rodríguez e Dolores Vilavedra (eds.) (2009), pp. [71]-101.

FERNÁNDEZ DEL RIEGO, Francisco (1995): Historia da Literatura. Vigo: Galaxia, pp. 212-217.

FERnÁNDEZ PÉREZ-SANJUlián, Carme (2003): A construción nacional no discurso literario de Ramón Otero Pedrayo. Vigo: A Nosa Terra.

Fernández ReI, Francisco (1990): Dialectoloxía da lingua galega. Vigo. Edicións Xerais de Galicia. Colección Universitaria.

FUNDACIÓN CARLOS CASARES: htpp://www.fundacioncarloscasares.org, última consulta: 2-II-2010.

GASPAR Porras, Silvia (2000): “A novela dende 1975”, en Tarrío Varela (coord.) (2000), cap. 3, pp. 96142.

LÓPEZ SÁNDEZ, María (2006): "Imaxinario paisaxístico e espazo urbano. Tensións e ambigüidades da inserción da cidade na narrativa galega", in Anuario Grial de Estudos Literarios Galegos. Vigo: Galaxia/Fundación Caixa Galicia, pp. 54-61.

Murado, Miguel Anxo (2008): Otra idea de Galicia. Barcelona: Debate.

Noia [CAMPOS], M Camiño (1975): “Xoguetes pra un tempo prohibido', por Carlos Casares”, en Grial, n. ${ }^{\circ}$ 50. Vigo: Galaxia, pp. 531-532.

(2000): “A narrativa de posguerra", en Tarrío Varela (2000). Vol. XXIV.

, Olivia Rodríguez e Dolores Vilavedra (eds.) (2009): Actas Simposio Carlos Casares. [A Coruña]: Fundación Carlos Casares.

Platas Tasende, Ana María (novembro 1998): “Conversación con Carlos Casares”, en Revista Galega do Ensino. 21, pp. 15-27.

Roig Rechou, Blanca-Ana (2004): "O contexto", in Carlos Casares, As laranxas máis laranxas de todas as laranxas. Versión e dirección de José Caldas. Santiago de Compostela: Xunta de Galicia/IGAEM, pp. 38-105.

SÁNCHEZ FERRACES, Xosé Luís (2007): “Os mortos daquel verán vinte anos despois da súa publicación”, in "Simposio Carlos Casares", Anuario Grial de Estudos Literarios Galegos. Vigo: Galaxia/Fundación Caixa Galicia, pp. 86-95.

SuCASAs, X. (1965): "Ma Xosé Queizán na nova narrativa galega”, Vieiros, 3, México. Ver ademais a opinión discordante de Casares en Álvarez Pousa (1969).

TARrío VARela, Anxo (1994): Literatura galega: Aportacións para unha Historia crítica. Vigo: Edicións Xerais de Galicia. Col. Universitaria. Manuais.

_ (coord.) (2000): Proxecto Galicia. Literatura. A Coruña: Hércules de Ediciones.

(2003): “A obra narrativa de Carlos Casares", en Revista galega do ensino. Santiago de Compostela: Xunta de Galicia, 38, pp. 115-145.

VILAVEDRA, Dolores (1999): Historia da Literatura galega. Vigo: Galaxia. 